\title{
Transitions to post-secondary and tertiary education in the Netherlands: a trend analysis of unconditional and conditional socio-economic background effects
}

\author{
Nicole Tieben • Maarten H. J. Wolbers
}

Published online: 15 November 2009

(C) The Author(s) 2009. This article is published with open access at Springerlink.com

\begin{abstract}
In the tracked educational system of the Netherlands, students at the end of secondary education have to decide whether they want to enter subsequent post-secondary or tertiary education. Depending on the previous qualification, they have the choice between up to four different options, including not entering further education. We propose, in line with prevalent theoretical approaches, that children from lower socio-economic backgrounds tend to make decisions that do not fully capitalize on their previously obtained qualifications. By means of multinomial logistic regression models we tested the unconditional and conditional effects of family background for entering the different tracks of post-secondary education. In the unconditional analyses we found effects for parental education on making a transition to all types of post-secondary and tertiary education, but the occupational status of the father seems to be only relevant for the transition to lower tier tertiary education. The conditional effects of parental education for making the transition to senior vocational education and university are strong, while the transition to lower tertiary education is not influenced by parental background characteristics. This shows that even with eligibility for the most prestigious tracks, children from lower socio-economic backgrounds tend to make less ambitious educational decisions. We also examined to what extent this inequality changed across time for the cohorts that terminated secondary education between 1932 and 1995. Decreasing effects of parental education indicate that the expansion of secondary education had the positive effect of leading more children from lower social backgrounds into favourable secondary education tracks, especially the intermediate general track. This equalization is carried forward through the entire sequence of educational transitions. The students from advantaged backgrounds nevertheless still profit from the parental resources in access to the most prestigious tertiary education
\end{abstract}

\footnotetext{
N. Tieben $(\bowtie)$

Faculty of Social Sciences, Department of Sociology, University of Mannheim, 68131 Mannheim, Germany

e-mail: n.tieben@uni-mannheim.de

M. H. J. Wolbers

Faculty of Social Sciences, Department of Sociology, Radboud University Nijmegen, P.O. Box 9104, 6500 HE Nijmegen, The Netherlands

e-mail: m.wolbers@maw.ru.nl
} 
institutions given secondary qualifications. Their head start into the academic track has not been reduced across cohorts.

Keywords The Netherlands · Vocational education - Tertiary education ·

Social inequality · Transitions · Conditional · Unconditional · Trend

\section{Introduction}

Research on the inequality of educational transitions unequivocally comes to the conclusion that entry to the prestigious institutions of tertiary education is highly socially selective. Children from more advantaged socio-economic backgrounds have higher chances to obtain eligibility for tertiary education but also, among all students who are eligible for tertiary education, they have higher chances to actually make the transition instead of entering the labour market after secondary education. The sequence of educational transition decisions that lead to the final educational attainment is captured in the so-called "Mare Model" (Mare 1980, 1981). This model, however, is derived from the Anglo-American educational system where a sequence of binary transition decisions determines the final educational attainment. More recent research (Lucas 2001; Breen and Jonsson 2000), however, emphasises the importance to apply multinomial transition models to take tracking into account. The division into different hierarchical tracks can be found in many educational systems. Two basically distinct types of tracking are prevalent (Müller and Wolbers 2003). A comprehensive secondary educational system with a tracking of certain performance levels in subjects like languages or mathematics is common in the U.S., while especially in Europe many systems have a structurally tracked secondary education, with a clear division of vocational and academic tracks. Breen and Jonsson (2000) could show how socio-economic background and the previous educational pathway influence the transition to either vocational or academic post-secondary education in Sweden. They propose a multinomial logit model with a simultaneous control of previous pathways within secondary education.

With this paper we contribute to existing research in two ways. First, we adapt the model proposed by Breen and Jonsson for the Dutch educational system and test the unconditional and conditional (that is, controlling for the obtained qualification level in secondary education) effects of socio-economic background for entering the different tracks of post-secondary education. The Dutch educational system resembles the Swedish in large parts, but still the model is not entirely applicable for the Dutch educational system. The Dutch educational system is tracked in both secondary and tertiary education and offers a multitude of different educational pathways (see Fig. 1). However, diplomas from one of the four secondary tracks each give specific eligibility for either vocational college (MBO), higher professional education (HBO) or university (WO). HBO is a lower tertiary track which is open for students with a HAVO or VWO diploma. University is exclusively for students with a VWO graduation. MBO is a post-secondary non-tertiary track, offering vocational training is various fields. Access to MBO is possible with a graduation from the two lower secondary tracks, LBO and MAVO. Dutch research mainly investigated the transition after graduation from one of the higher secondary tracks (HAVO and VWO), which give eligibility for tertiary education and focused on the decision between the higher vocational track (HBO) and university (Bosma and Cremers 1996; Webbink 1997; de Graaf and Wolbers 2003; Korteweg et al. 2003). This research ignores a very large proportion of the Dutch population that did not obtain a graduation from one of 


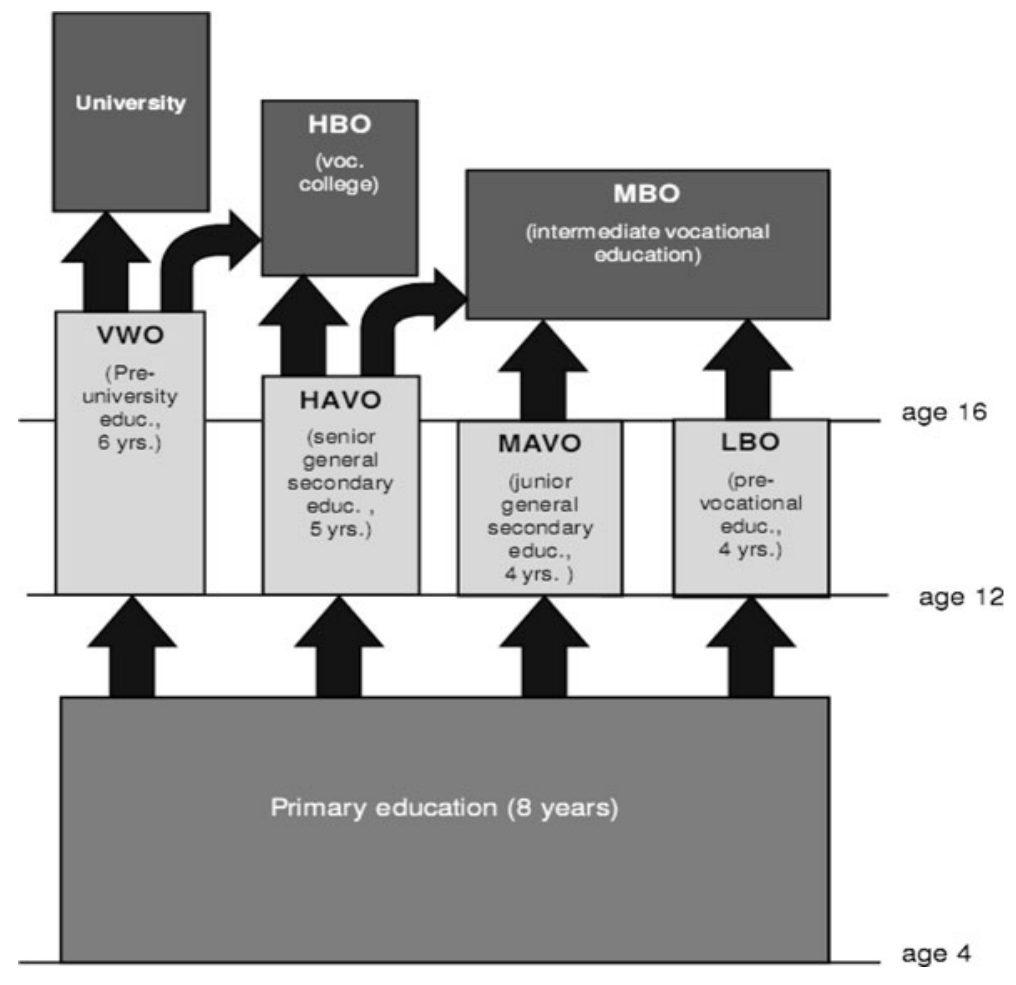

Fig. 1 The Dutch educational system

the higher secondary tracks. Even in recent cohorts, the proportion of students who did not obtain eligibility for tertiary education is more than $50 \%$. The more common educational pathway is a lower (LBO) or intermediate (MAVO) secondary education graduation, followed by a vocational course at senior vocational school (MBO). But not only graduates from the lower and intermediate secondary tracks enter MBO, also students who are in fact eligible to enter tertiary education may decide to choose this track. A considerable proportion of students in fact chooses a track of subsequent education below their actual eligibility. Previous research (Rijken et al. 2007) suggests that especially children from less advantaged socio-economic backgrounds tend to choose less ambitious.

Second, we investigate in how far the social inequality in transitions to post-secondary and tertiary education changes over time. A massive expansion in secondary education leads to an increased proportion of students who are eligible to enter tertiary tracks. This may result in a bottleneck at the transition to subsequent education when this growth is not absorbed by tertiary education institutions ("Maximally Maintained Inequality", cf. Raftery and Hout 1993). Previous research, in which the traditional sequential transition model (Mare 1980) has been used, concludes that in several countries indeed stable or even increased socio-economic background effects in the advanced transitions are found, despite a decrease of inequality in final educational attainment across cohorts [de Graaf and Ganzeboom (1993) for the Netherlands; Jonsson (1993) for Sweden; Müller and Haun (1994) for Germany]. These studies either merge all tertiary tracks and apply binary logit models or focus on one single academic track which is most prestigious and exclusive. 
Theories of educational decision making suggest, however, that in cases of "low-cost-lowrisk" alternatives to universities especially the students from lower socio-economic backgrounds are attracted by these alternatives (Shavit et al. 2007). In sum, they thus profit from the expansion of secondary education, as they face improved educational opportunity in an absolute sense, but nevertheless remain in their unfavourable relative position regarding the disadvantages compared to children from privileged backgrounds ("Effectively Maintained Inequality", cf. Lucas 2001). As in the Netherlands two kinds of institutions offer education at tertiary level (HBO and WO), this problem may be mitigated by streaming students into different levels, but maintaining the exclusiveness of elite institutions. Recent research pointed out that transitions to tertiary education in a conditional setting (that is, given eligibility) are considerably less socially selective than earlier transitions in the educational career (Breen and Jonsson 2000).

To answer these two research questions and to test the accompanying hypotheses, we use four Dutch retrospective life-history datasets in the empirical part of this paper with full information on the educational career of more than 6,000 individuals, who entered post-secondary and tertiary education in the Netherlands in the period 1932-1995.

\section{Inequality in educational transitions}

Theories of educational decisions (Boudon 1974) suggest that students (and their parents) not only base their school continuation decisions on the available financial and cultural resources, but also on a background-specific perception of success probability. Besides, parents strive to maintain the families' status and therefore want their children to obtain at least the same educational level as their own ("relative risk aversion", cf. Erikson and Jonsson 1996; Breen and Goldthorpe 1997; Stocké 2007; van der Werfhorst and Hofstede 2007). In meritocratic societies, the probability of reaching a high occupational status can be maximised through high educational attainment. Children from high status backgrounds, therefore, have a strong incentive to choose the most promising educational pathways. Children from lower status backgrounds can maintain the parental status with less educational investment, because lower or intermediate diplomas are sufficient to reach the low parental status. This theoretical approach is used to explain the "lack of educational aspiration" in low-status groups. In line with Boudons' argument that inequality is a result of a sequence of several educational decisions, Mare (1980) proposed a sequential transition model. Based on these considerations, researchers of inequality of educational opportunity investigated the effects of parental background on separate educational transitions rather than final educational attainment. With their extensive comparison of 13 countries Shavit and Blossfeld (1993) revealed that these background-specific decision patterns can be observed in all 13 countries with different types of educational systems and political settings. Another finding was that inequality decreased across transitions-effects of parental background are consistently lower in later than in early transitions. The main shortcoming of this model, however, is that it assumes binary stay-or-leave decisions, which in fact do not reflect the tracked nature of most educational systems. Tracking can be found in the post-secondary education of most countries, but in some systems, like for example in Germany, Austria, Switzerland and the Netherlands, we find a division of different tracks in secondary school, too. Most other countries with a comprehensive secondary school system, however, do have tracked structure in some subjects, like languages and mathematics. Recent research (Breen and Jonsson 2000; Lucas 2001) pointed at the relevance to take this tracking into account for two reasons. First, track allocation is most likely to be 
background-specific and leads advantaged children into more favourable tracks. Lucas (2001) emphasises that tracking research may reveal horizontal stratification within secondary education. Second, initial track allocation to a very large extent determines the future options for subsequent education. As a result, inequality accumulates over the educational career because of an unfavourable initial track placement (Hillmert and Jacob 2003).

Due to the multi-track structure of the Dutch educational system and the early allocation to secondary tracks at the age of 12 years, educational inequality in the Netherlands can be observed very early in the life course (Dronkers 1983; Vrooman and Dronkers 1986; Faasse et al. 1987). In the course of secondary education this initial inequality is enhanced by socially selective intra-secondary transitions and a background-specific dropout propensity (Jacob and Tieben 2007; Tieben and Wolbers 2008).

As outlined above, admission to one of the three types of post-secondary/tertiary education is strictly regulated and depends on the qualification obtained in secondary education. Access to tertiary education is reserved for students who hold at least a graduation from HAVO and for university entry a VWO diploma is required. For this reason, the choice of a secondary track at the end of primary education can constrain the choice options for later transitions. The social inequality that can be found in transitions to postsecondary/tertiary education to a large extent is a consequence of the previous transitions. For these reasons, we have to expect social selectivity in post-secondary/tertiary track choice and propose the following hypothesis:

H1 As the eligibility for post-secondary/tertiary education is strictly related to the qualification level obtained in secondary education, we expect positive effects of socioeconomic background on the transition to post-secondary/tertiary education.

The choice of the educational pathway after secondary school is, as predicted by the first hypothesis, restricted by previously obtained eligibility, but not fully determined, as a transition to a track below the obtained qualification level is always possible in the Dutch educational system. No matter which of the four secondary education diplomas has been obtained, the student always has at least two options. LBO and MAVO graduates, can continue in $\mathrm{MBO}$ or leave the educational system altogether. HAVO graduates can chose between $\mathrm{HBO}$, which would be appropriate regarding the formal qualification, $\mathrm{MBO}$ which is a less demanding, less risky but also less profitable option and leaving. VWO graduates have the choice between a traditional university (appropriate), HBO (below qualification), MBO (far below qualification) and leaving education. We propose that, given previous qualifications, the same decision patterns that produce the social selectivity in the transitions during secondary education, also apply in the later transitions to post-secondary/ tertiary education. We expect that-given previous qualifications-especially children from lower socio-economic backgrounds tend to make less ambitious educational choices than children from advantaged backgrounds and derive the following hypothesis:

H2 Given the qualification level obtained in secondary education, children from lower socio-economic backgrounds are more likely to enter a track in post-secondary/tertiary education that is below their actual eligibility than children from advantaged backgrounds.

\section{Trends in inequality}

De Graaf and Ganzeboom (1993) report decreasing effects of the educational level and the occupational status of the father on obtaining graduation from any kind of secondary 
education in the Netherlands, but stable effects for obtaining a graduation from higher secondary education, which gives eligibility for tertiary education. Taking eligibility into account in a conditional model of transitions to tertiary education, their binary logistic regression models revealed that access to tertiary education remains exclusive as well. As outlined above, however, recent research points at the necessity to take into account that many educational systems are tracked and to apply multinomial logistic regression analysis for the assessment of inequality in educational transitions (Lucas 2001; Breen and Jonsson 2000). However, this research does not scrutinize on trends over time. There have been several attempts to scrutinize on the changes of social selectivity over time within tracked educational systems, but these merely focus on the secondary level and do not take subsequent decision patterns into account (Schimpl-Neimanns 2000; Tieben et al. 2009; Tieben and Wolbers 2008). Schimpl-Neimanns (2000) investigated social inequality and its trends in the transitions to different secondary tracks in Germany and found that inequality decreased in access to the lower tracks of secondary education, but that the academic track of secondary education (Gymnasium) remained exclusive. Tieben et al. (2009) come to a similar conclusion for the Dutch educational system. Besides, these authors found that the growth in educational participation for cohorts that entered secondary education between 1946 and 1998 mainly took place in MAVO and HAVO and that access-selectivity decreased only in these tracks, while access to VWO remained exclusive. Tieben and Wolbers (2008) found that the background effects on obtaining a graduation from a given secondary track are partly explained by initial track choice and subsequent intra-secondary transitions. They did, however, observe autonomous effects of parental education on obtaining eligibility for tertiary education (versus dropping out altogether), which indicates that children with highly educated parents profit more from the educational resources of their parents, even conditional on initial track choice and intrasecondary transitions. The observed trends in background effects on graduation from secondary tracks, on the other hand, are entirely explained by decreasing inequality in initial track choice. These trends suggest that from an unconditional perspective, the social selectivity in the transition to post-secondary/tertiary education might decrease as wellconsidering the fact that the inequality in obtaining eligibility to enter post-secondary/ tertiary tracks is less depending on socio-economic background in more recent cohorts. Unless these trends are counteracted by increasing inequality in the conditional transition, they are carried forward to the subsequent transitions. We therefore suggest that:

H3 Positive effects of socio-economic background on the transition to post-secondary/ tertiary education decrease over time for entry into $\mathrm{MBO}$ and $\mathrm{HBO}$, but not for entry into university.

Rijken et al. (2007) reported that inequality in access to MBO (senior vocational education) decreased between 1977 and 1993, but that the proper tertiary tracks, HBO (vocational college) and university remained exclusive. They outlined in how far the expansion of a tracked educational system and the consequent redistribution of students to different tracks may alter the composition of the "risk groups" for making transitions to post-secondary education. While Mare (1993) argued that the increased heterogeneity in terms of unmeasured features of the risk group would cause increasing background effects across cohorts in a sequential transition model with binary transition decisions, it is hard to predict in how far educational expansion causes shifts in the track-composition in a tracked system. Nevertheless, it can be expected that the transition to MBO becomes less selective for two reasons. First, even for children from low educated backgrounds it becomes increasingly crucial to obtain vocational education and to make the transition to MBO, 
given the process of skills upgrading in modern labour markets. Second, the student population that obtains eligibility for MBO (that is, LBO and MAVO graduates) becomes increasingly homogenous in terms of parental background and unmeasured features, because the brightest children from lower social backgrounds meanwhile rather opt for HAVO instead of the lower secondary tracks. For these reasons, we predict that inequality in access to $\mathrm{MBO}$ decreases across cohorts. However, the lower class children that obtained a HAVO-diploma in recent decades (due to the educational expansion that has taken place) may have disadvantages in terms of resources when they have to decide between HBO, MBO or labour market entry. The Dutch government supports students with grants and loans and increased these in 1986, but, on the other hand, the tuition fees have increased continuously and despite this governmental support, parents face substantial costs of living and opportunity costs. Despite the increased opportunity to enter HBO for children from lower socio-economic backgrounds, these may still decide to use their qualification to enter MBO which is less costly or directly enter the labour market. The same applies for VWO graduates who have to decide whether they want to enter university or HBO. Lower class VWO graduates may be discouraged by the abstract theoretical curricula of traditional universities and rather enter the more practically oriented HBO. As the labour market prospects for HBO-graduates are quite good and this educational programme requires less direct and opportunity costs, this may be the more attractive alternative to university. For these reasons, we expect that:

H4 Conditional positive effects of socio-economic background on the transition to postsecondary/tertiary education decrease over time for entry into MBO, but not for entry into $\mathrm{HBO}$ and university.

\section{Data and variables}

We use the Family Survey Dutch Population (FSDP), a four wave (1992, 1998, 2000, 2003) repeated cross-sectional survey of a representative sample of the Dutch population. This dataset contains detailed retrospective information on the complete educational careers of approximately 7,500 respondents. For each respondent we have up to 10 education records with information about the start and ending date, the track, whether it was a full-time programme and terminated with a diploma. We excluded all records that started before the age of 10 and after the age of 25 , that had duration of longer than 9 years, or that were not referring to secondary or post-secondary education. Education records that concerned a part-time programme or started after labour market entry were excluded as well, just as respondents who were still in secondary education and have not obtained a secondary diploma before the time of the interview. We also corrected (pooled) lateral transitions and excluded all respondents with incomplete information on the relevant variables. We excluded all respondents form the dataset who were younger than 22 years at the time of the interview. This is in order to avoid a bias caused by delayed educational careers (grade retention, gap years, etc.). The resulting dataset contains information of in total 6,047 respondents. For our analysis, we use those 5,049 respondents who obtained a diploma from a secondary education track.

The dependent variable has four categories: $\mathrm{MBO}, \mathrm{HBO}$, university and no further education. MBO programmes with duration of $<3$ years were coded as "no further education", as these usually do not result in a full labour market qualification. There have been some changes in the structure of the Dutch educational system throughout the entire period 
Table 1 Overview of old (pre-reform) and new (post-reform) tracks

\begin{tabular}{lll}
\hline Level & Before WVO & After WVO \\
\hline Lower secondary & Huishoudsschool & LBO (4 years) \\
& Ambachtsschool & MAVO (4 years) \\
& ULO (3-4 years) & \\
Intermediate secondary & MULO (3-4 years) & HAVO (5 years) \\
Pre-academic secondary & Mas (5 years) & \\
& Handelsdagschool (4 years) & VWO (6 years) \\
& Gymnasium (6 years) & \\
& Lyceum (6 years) & \\
& Athenaeum (6 years) & \\
\hline
\end{tabular}

under investigation. Especially the institutions that offer non-tertiary vocational training change their curriculums and programmes continuously in order to meet the requirements of the changing labour market, so that a number of different types of senior vocational schools are subsumed as MBO. However, all the programmes have in common that they last at least 3 years and lead to a full labour market qualification. In the same way institutions of secondary education underwent changes. For reasons of readability we maintain the current naming of school types but subsumed comparable historical school types under the same label. View Table 1 for an overview of all historical school types that have been subsumed under the labels used here.

Socio-economic background is measured as the parental level of education and the occupational status of the father. We retrieved the educational level of the highest educated parent and converted this to an interval scale. The original range of this variable was 6-21 years (that is, the minimum number of years that is necessary to obtain this educational level). The occupational status of the father is based on the International SocioEconomic Index of Occupational Status (ISEI) developed by Ganzeboom et al. (1992). The original range is 10-90. For the sake of comparison, both socio-economic background characteristics have been rescaled to a 0-1 range. Furthermore, we used the year of terminating secondary education (varying between 1932 and 1995). This variable is constructed as five cohort-dummies. The dummies vary in length in order to obtain a sufficient number of cases in each cohort. We also defined dummies for the qualification level obtained in secondary education. For those respondents who obtained more than one diploma in secondary education, the highest of all diplomas was used. The highest secondary diploma is categorized as LBO (including the former Huishoudsschool and Ambachtsschool), MAVO (including the former ULO and MULO), HAVO (including the former MMS) and VWO (including the former HBS, gymnasium, atheneum and lyceum).

\section{Results}

Bivariate analyses

The left panel of Fig. 2 displays the highest obtained secondary education diploma and the right panel of this figure shows the transition rates to post-secondary education across cohorts. Educational expansion is manifest in a decrease of drop out at the end of secondary education ("no diploma") and an increase of a higher secondary diploma (HAVO 

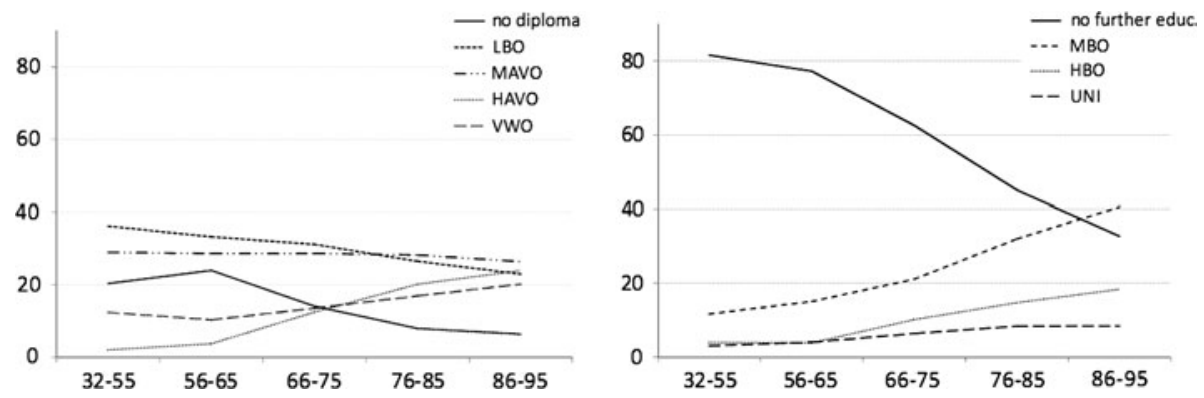

Fig. 2 Distribution of qualification level obtained in secondary education (left panel) and entry rates in post-secondary education (right panel) by year of terminating secondary education (\%)

and VWO), while the share of lower secondary (LBO and MAVO) diploma decreases over time.

Looking at the transitions to post-secondary education, we observe that the share of students who do not choose further education decreases dramatically. Participation in all post-secondary education tracks increases over time. One consequence of the growth of the two higher secondary tracks is an increase of students who are eligible to enter the tertiary tracks HBO and university. Therefore, the increase of participation in these tracks is plausible. We also observe a very strong increase in the participation in MBO. So, it is worthwhile to have a closer look at the specific destination distributions for each of the four qualification levels in secondary education.

Figure 3 shows the distribution of graduates from the four different types of secondary education on the transition outcomes per cohort. The risk of not obtaining additional vocational or tertiary education after secondary education decreases for graduates from all secondary tracks. We find that for LBO and MAVO graduates, the transition rates to MBO increase drastically over time. Despite this massive improvement of transition probability, the chance for LBO graduates of not obtaining additional vocational training even in the youngest cohort is high at $46 \%$. For HAVO graduates, the chance of making a transition to
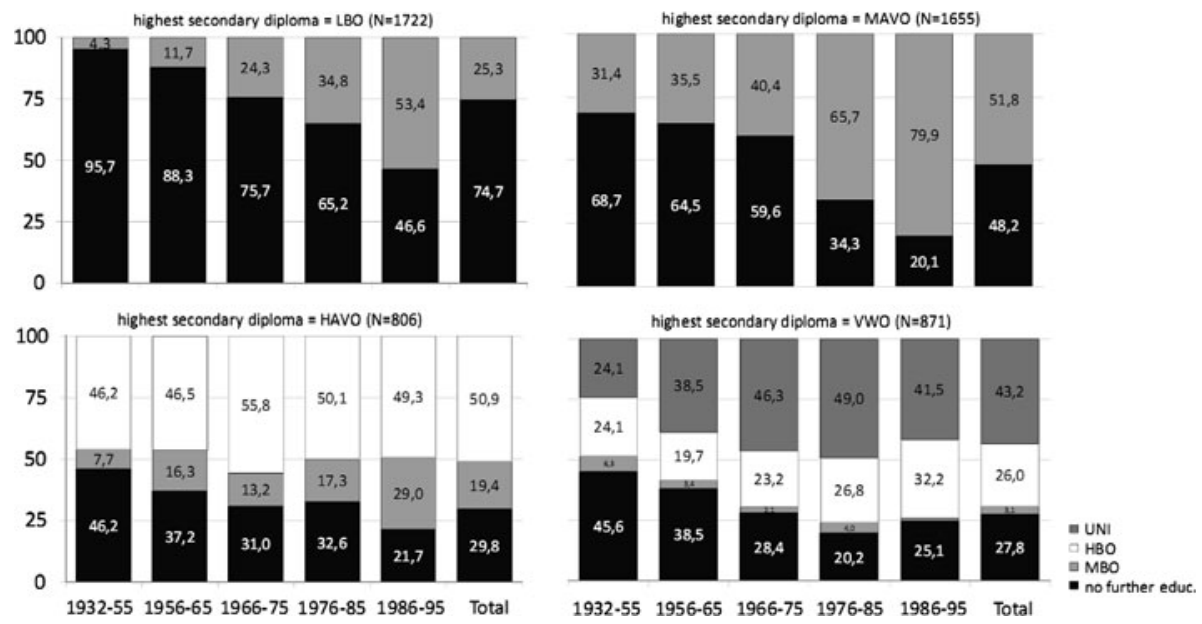

Fig. 3 Track specific destinations after graduation from secondary education by year of terminating secondary education $(\%)$ 
HBO fluctuates around 50\% without a clear upward or downward trend across cohorts, while the chance of entering MBO increases. Among VWO graduates, only a very small percentage enters MBO. Most interesting in this group is the observation that the rate of university entry increases until the 1966-1975 cohort, while the transition rate to HBO remains stable. Surprisingly, in the later cohorts this is reversed and $\mathrm{HBO}$ grows, while the entry rate for university education decreases. For HAVO and VWO graduates, we thus find a growing tendency in later cohorts to enter subsequent education below actual eligibility. It is doubtful, however, to interpret these as unambitious choices, as for HAVO graduates the choice of MBO seems to be rather an alternative to no further education than an alternative to HBO. For VWO graduates, the interpretation that $\mathrm{HBO}$ diverts students from university may be partly justified, but here too, entering HBO possibly is rather an alternative to not entering further education at all for students who are reluctant to enter university.

\section{Multivariate analyses}

We start to estimate a set of binary logistic regression models on all respondents to test the effects of socio-economic background for making a transition to any kind of

Table 2 Binary logistic regression on making a transition to post-secondary education (logit coefficient)

\begin{tabular}{|c|c|c|c|c|}
\hline & MI & MII & MIII & MIV \\
\hline Intercept & $-0.46 * * *$ & $0.68 * * *$ & $-0.31 * *$ & $0.80 * * *$ \\
\hline Sex $($ female $=1)$ & $-0.21 * * *$ & $-0.25 * * *$ & $-0.22 * * *$ & $-0.26 * * *$ \\
\hline \multicolumn{5}{|c|}{ Year terminating secondary educ. } \\
\hline $1932-1955$ & $-1.47 * * *$ & $-1.43 * * *$ & $-2.05 * * *$ & $-1.90 * * *$ \\
\hline $1956-1965$ & $-1.14^{* * *}$ & $-1.07 * * *$ & $-1.53 * * *$ & $-1.39 * * *$ \\
\hline 1966-1975 & $-0.61 * * *$ & $-0.57 * * *$ & $-0.81 * * *$ & $-0.74 * * *$ \\
\hline \multicolumn{5}{|l|}{ 1976-1985 (ref.) } \\
\hline 1986-1995 & $0.43 * * *$ & $0.46^{* * *}$ & $0.69 * * *$ & $0.68 * * *$ \\
\hline Education parents $(0-1)$ & $2.11 * * *$ & $1.40 * * *$ & $4.10 * * *$ & $3.38 * * *$ \\
\hline Occupation father (ISEI 0-1) & $0.88 * * *$ & 0.32 & $1.19 *$ & $0.36 * * *$ \\
\hline Trend education parents ${ }^{\mathrm{a}}$ & & & $-0.63 * * *$ & $-0.62 * * *$ \\
\hline Trend occupation father ${ }^{b}$ & & & -0.09 & 0.00 \\
\hline LBO graduate & & $-1.60 * * *$ & & $-1.58 * * *$ \\
\hline MAVO graduate & & $-0.50 * * *$ & & $-0.49 * * *$ \\
\hline HAVO graduate & & -0.18 & & -0.17 \\
\hline \multicolumn{5}{|l|}{ VWO graduate (ref.) } \\
\hline$N$ & 5,049 & 5,049 & 5,049 & 5,049 \\
\hline$-2 \mathrm{LL}$ & $-3,049.9$ & $-2,876.5$ & $-3,036.2$ & $-2,865.4$ \\
\hline Pseudo $R^{2}$ & 0.13 & 0.18 & 0.13 & 0.18 \\
\hline
\end{tabular}

$* p<0.05$; ** $p<0.01$; *** $p<0.001$

a The trend is modeled as a linear interaction of education parents $(0-1) \times$ year terminating secondary education

b The trend is modeled as a linear interaction of occupation father $(0-1) \times$ year terminating secondary education 
post-secondary education. Table 2 shows the logit coefficients of these models. Model I first of all reveals that girls have a lower chance to make a transition to post-secondary/ tertiary education than boys. Second, it is found that transition rates increase over time, indicating the general educational expansion. Third, children from advantaged socioeconomic backgrounds are more likely to enter post-secondary education, as predicted by $\mathrm{H} 1$, but effects of parental education are stronger than effects of father's occupational status. Controlling for the qualification level obtained in secondary education (see Model II), we find that the effects of parental education are to a large extent explained by the secondary education diploma, but that there are some autonomous effects of parental education even when diploma level is controlled for. The effects of the occupational status of the father are entirely explained by the qualification level in secondary education. We find that LBO graduates have the smallest chance of making a transition to post-secondary education and that the transition rate of HAVO graduates does not differ from that of VWO graduates. In the Models III and IV, we introduced linear trends for the effects of the socioeconomic background variables. The trends are modelled as linear interactions between parents' education and fathers' occupation on the one hand and year of terminating secondary education on the other. The year of terminating secondary education is represented here as an interval variable ranging from the value 0 (for the cohort 1932-1955) to 4 (for the cohort 1986-1995). The effects of parental education decrease significantly over time, while there is no decrease of the effects of father's occupational status (see Model III). However, the effect of parental education for the first cohort (main effect in the model) is considerably larger than the effect of the occupational status of the father in the same cohort. Controlling for secondary education diploma in Model IV, we do not observe any effects on the trend itself. We thus may conclude that the decreasing effects of parental education on making any transition to post-secondary education is not induced by a shift in the social selectivity of eligibility.

Table 3 displays the results of multinomial logit models predicting the possible destinations in post-secondary education. The reference category is not entering further education after terminating secondary education. The table shows alternating models without trends (Model I) and with linear trends for the effect of parental education and father's occupational status (Model II). We first of all find a negative effect for females for making the transition to the university. In addition, we observe an increase of transition chances relative to not entering subsequent education across cohorts. Furthermore, and again in accordance with $\mathrm{H} 1$, it is found that parental education is relevant for transitions to any subsequent education, while the occupational status of the father is only beneficial for entering tertiary education (that is, $\mathrm{HBO}$ and university). According to Model 2, we do observe a decrease of parental education effects across cohorts for entering MBO and $\mathrm{HBO}$, but not for university. Social inequality thus decreases for the two intermediate tracks, while the most prestigious option, university education, remains exclusive. This finding corroborates $\mathrm{H} 3$.

The above models show the transition rates for all students, irrespective of their eligibility. As outlined earlier, the options for making a transition to subsequent education in the Netherlands are severely restricted by the previously obtained qualifications. We therefore split the data into the four possible secondary graduation levels. As it is possible to obtain more than one secondary education diploma, especially for the purpose to obtain a higher qualification after the first secondary graduation (supplement diploma), only the highest (in most cases: the last) secondary education graduation is taken into account. These conditional models show in how far the social inequality in transition rates regarding post-secondary education is explained by inequality in previous transitions during the 
Table 3 Unconditional multinomial logistic regression on making a transition to different post-secondary tracks (logit coefficients)

\begin{tabular}{|c|c|c|c|c|c|c|}
\hline & \multicolumn{2}{|c|}{ MBO vs. no further educ. } & \multicolumn{2}{|c|}{$\begin{array}{l}\text { HBO vs. no further } \\
\text { educ. }\end{array}$} & \multicolumn{2}{|c|}{$\begin{array}{l}\text { University vs. no } \\
\text { further educ. }\end{array}$} \\
\hline & Model I & Model II & Model I & Model II & Model I & Model II \\
\hline Intercept & $-0.53 * * *$ & $-0.36^{* *}$ & $-2.45 * * *$ & $-2.28 * * *$ & $-3.58 * * *$ & $-3.48 * * *$ \\
\hline Sex $($ female $=1)$ & -0.08 & -0.09 & -0.10 & -0.11 & $-1.11 * * *$ & $-1.12 * * *$ \\
\hline \multicolumn{7}{|l|}{ Year terminating secondary educ. } \\
\hline $1932-1955$ & $-1.42 * * *$ & $-2.06 * * *$ & $-1.70 * * *$ & $-2.52 * * *$ & $-1.41 * * *$ & $-1.64 * *$ \\
\hline 1956-1965 & $-1.05 * * *$ & $-1.49 * * *$ & $-1.60 * * *$ & $-2.13 * * *$ & $-0.95 * * *$ & $-1.09 * *$ \\
\hline $1966-1975$ & $-0.64 * * *$ & $-0.87 * * *$ & $-0.59 * * *$ & $-0.86^{* * *}$ & $-0.56 * * *$ & $-0.62 * *$ \\
\hline \multicolumn{7}{|l|}{ 1976-1985 (ref.) } \\
\hline 1986-1995 & $0.51 * * *$ & $0.81 * * *$ & $0.40 * *$ & $0.72 * * *$ & 0.12 & 0.21 \\
\hline Education parents $(0-1)$ & $1.34 * * *$ & $3.45^{* * *} *$ & $2.62 * * *$ & $4.92 * * *$ & $4.21 * * *$ & $5.85 * * *$ \\
\hline Occupation father (ISEI 0-1) & 0.20 & 0.75 & $1.80 * * *$ & $2.28 *$ & $2.39 * * *$ & 1.97 \\
\hline Trend education parents & & $-0.66 * * *$ & & $-0.70 * *$ & & -0.52 \\
\hline Trend occupation father & & -0.16 & & -0.13 & & 0.11 \\
\hline$N$ & 5,049 & 5,049 & & & & \\
\hline$-2 \mathrm{LL}$ & $-5,190.1$ & $-5,174.2$ & & & & \\
\hline Pseudo $R^{2}$ & 0.11 & 0.12 & & & & \\
\hline
\end{tabular}

$* p<0.05 ; * * p<0.01 ; * * * p<0.00$

educational career and to what extent autonomous socio-economic background effects remain when eligibility is controlled for.

Table 4 shows that, taking the qualification level in secondary education into account, the transition rates for $\mathrm{LBO}$ and MAVO graduates into MBO increase over time. Girls that graduated from MAVO have a disadvantage in entering MBO, but for LBO graduates we do not observe such a gender effect. We also find effects of parental education for LBO and MAVO graduates in entering MBO, but the father's occupational status seems not to be relevant in this decision. Looking at HAVO graduates, we find that females are more likely than males to leave the educational system instead of entering subsequent education in $\mathrm{HBO}$, but gender is not relevant in the decision between MBO and $\mathrm{HBO}$. We do not find an effect of time for entering $\mathrm{HBO}$ except from a small negative effect in the youngest cohort in the HBO versus MBO contrast. For VWO graduates, who are eligible for university, the table provides the contrast university versus no further education and university versus HBO. For both contrasts we find a disadvantage of female students in entering university. Not entering any further education instead of university gets increasingly unpopular among VWO graduates, but we do not find a similar growth of the relative transition rates for the HBO contrast. Parental education has a considerable effect on making the transition to the university compared to not entering further education and also in the decision between $\mathrm{HBO}$ and university. With respect to VWO graduates, this result supports $\mathrm{H} 2$.

Conditional upon the qualification level in secondary education, we do not find any trend in the effects of the socio-economic background characteristics on the destination in post-secondary education. As is shown in "Appendix", none of the included interaction terms deviates significantly from the value zero. We, therefore, cannot confirm $\mathrm{H} 4$. 
Table 4 Conditional multinomial logistic regression on making a transition to different post-secondary tracks (b coeff.)

\begin{tabular}{|c|c|c|c|c|c|c|}
\hline & \multirow{2}{*}{$\begin{array}{l}\text { LBO } \\
\text { graduates } \\
\text { MBO vs. } \\
\text { no further } \\
\text { educ. }\end{array}$} & \multirow{2}{*}{$\begin{array}{l}\text { MAVO } \\
\text { graduates } \\
\text { MBO vs. no } \\
\text { further educ. }\end{array}$} & \multicolumn{2}{|c|}{ HAVO graduates } & \multicolumn{2}{|c|}{ VWO graduates } \\
\hline & & & $\begin{array}{l}\text { HBO vs. } \\
\text { no further } \\
\text { educ. }\end{array}$ & $\begin{array}{l}\text { HBO vs. } \\
\text { MBO }\end{array}$ & $\begin{array}{l}\text { University } \\
\text { vs. no } \\
\text { further educ. }\end{array}$ & $\begin{array}{l}\text { University } \\
\text { vs. HBO }\end{array}$ \\
\hline Intercept & $-1.36^{* * *}$ & $0.33 *$ & 0.13 & $0.67 *$ & 0.47 & 0.03 \\
\hline Sex $($ female $=1)$ & 0.17 & $-0.51 * * *$ & $-0.35^{*}$ & -0.36 & $-0.84^{* * *}$ & $-0.92 * * *$ \\
\hline \multicolumn{7}{|c|}{ Year terminating secondary educ. } \\
\hline $1932-1955$ & $-2.28 * * *$ & $-1.38 * * *$ & -0.58 & 0.55 & $-1.66^{* * *}$ & $-0.76^{*}$ \\
\hline $1956-1965$ & $-1.25 * * *$ & $-1.25 * * *$ & -0.20 & -0.02 & $-1.02 * * *$ & -0.10 \\
\hline $1966-1975$ & $-0.43 * *$ & $-1.02 * * *$ & 0.14 & 0.36 & $-0.48^{*}$ & -0.02 \\
\hline \multicolumn{7}{|l|}{ 1976-1985 (ref.) } \\
\hline 1986-1995 & $0.64 * * *$ & $0.72 * * *$ & 0.37 & $-0.55^{*}$ & -0.47 & -0.43 \\
\hline Education parents $(0-1)$ & $2.23 * * *$ & $1.63 * * *$ & 0.81 & 0.52 & $1.46^{* * *}$ & $1.38 * *$ \\
\hline $\begin{array}{l}\text { Occupation father } \\
\text { (ISEI 0-1) }\end{array}$ & 0.55 & 0.45 & 0.50 & 0.90 & 0.30 & 0.73 \\
\hline$N$ & 1,722 & 1,650 & 806 & & 871 & \\
\hline$-2 \mathrm{LL}$ & -841.96 & $-1,006.2$ & -802.56 & & -960.38 & \\
\hline Pseudo $R^{2}$ & 0.14 & 0.12 & 0.03 & & 0.06 & \\
\hline
\end{tabular}

$* p<0.05 ; * * p<0.01 ; * * * p<0.001$

\section{Conclusions and discussion}

In this paper, we studied effects of socio-economic background on transitions to postsecondary education in the Netherlands. Previous research suggests that the transition to secondary education is determined to a large extent by socio-economic background characteristics such as the educational level of the parents and occupational status of the father. All subsequent transitions are depending on the choice of the initial track in secondary education, as the eligibility to enter post-secondary or tertiary education is strictly related to previous qualifications. It is therefore logical to expect socio-economic background effects on transitions to post-secondary education as well. In fact, the empirical analysis showed unconditional effects of the parental level of education and the occupational status of the father on the decision whether to enter post-secondary education at all and, if yes, on the choice of track within post-secondary or tertiary education. It was found that the impact of parental education is much stronger than the effect of father's occupation. Moreover, unlike parental education, the occupational status of the father is not relevant for the decision between $\mathrm{MBO}$ (senior vocational training) and not entering postsecondary education.

In addition, it was predicted that conditional upon the same eligibility for subsequent education, children from lower socio-economic backgrounds tend to make more cautious educational decisions than those from advantaged backgrounds. The Dutch educational system provides a choice of several post-secondary tracks to choose from, which differ in standards and prestige. Our analysis revealed that, given the previously 
obtained secondary qualification, children from advantaged socio-economic backgrounds are indeed more likely to enter an appropriate track, while children from lower socioeconomic background have a stronger tendency to choose a track below eligibility or abandon subsequent education altogether. Again, the occupational status of the father is not relevant here. Most interestingly, graduates from HAVO make their subsequent educational decision independently of parental education while the effect of the parental level of education is positive and rather strong for graduates originating from all other secondary tracks.

Second, we investigated to what extent the observed social inequality in transitions to post-secondary and tertiary education has changed over time. After the massive expansion of secondary education in the Netherlands in the last decades, the inequality of educational opportunity with regard to the transition to lower and intermediate secondary tracks has decreased, while access to the highest track, VWO, remained exclusive for children from higher socio-economic backgrounds. We therefore expected the unconditional effects of socio-economic background on the likelihood of entering MBO and HBO to decrease as well. This hypothesis is partly confirmed. It was found that effect of parental education on the transition to MBO and HBO decreased over time, while the effect of father's occupational status remained stable. This, however, is due to the decreasing inequality in obtaining eligibility for $\mathrm{MBO}$ and $\mathrm{HBO}$. When secondary education qualification, and therefore eligibility was taken into account, no decrease in the effect the parental level of education was observed. This partly confirms the hypothesis that inequality of educational opportunity should decrease for the transition to $\mathrm{MBO}$, but not for the proper tertiary tracks, $\mathrm{HBO}$ and university.

In sum, the empirical analysis of this paper demonstrated that socio-economic background effects are present in both unconditional and conditional transition decisions regarding enrolment in post-secondary education in the Netherlands. It is evident that in the Dutch context, as in other countries with a multi-track structured educational system, the most crucial educational decision lies in the choice of a secondary education track after primary school, as this to a very large extent determines the future options for subsequent transitions. But also once a qualification in secondary education is obtained, the parental background still does have a considerable influence on the choice between the available post-secondary options. In particular, the observed conditional effects of socio-economic background in case of alternatives to university suggest that especially students from lower socio-economic backgrounds are attracted by these alternatives. They thus profit from the expansion of secondary education, as they face improved educational opportunity in an absolute sense, but nevertheless remain in their unfavourable relative position regarding the disadvantages compared to children from privileged backgrounds. In this way, socioeconomic background effectively maintains inequality of educational opportunity, as it was claimed by Lucas (2001).

Open Access This article is distributed under the terms of the Creative Commons Attribution Noncommercial License which permits any noncommercial use, distribution, and reproduction in any medium, provided the original author(s) and source are credited.

\section{Appendix}

See Table 5. 
Table 5 Trend models

\begin{tabular}{|c|c|c|c|c|c|c|}
\hline & \multirow{2}{*}{$\begin{array}{l}\text { LBO } \\
\text { graduates } \\
\text { MBO vs no } \\
\text { further educ. }\end{array}$} & \multirow{2}{*}{$\begin{array}{l}\text { MAVO } \\
\text { graduates } \\
\text { MBO vs no } \\
\text { further educ. }\end{array}$} & \multicolumn{2}{|c|}{ HAVO graduates } & \multicolumn{2}{|l|}{ VWO graduates } \\
\hline & & & $\begin{array}{l}\text { HBO vs no } \\
\text { further educ. }\end{array}$ & $\begin{array}{l}\text { HBO vs } \\
\text { MBO }\end{array}$ & $\begin{array}{l}\text { University vs no } \\
\text { further educ. }\end{array}$ & $\begin{array}{l}\text { University } \\
\text { vs HBO }\end{array}$ \\
\hline Intercept & $-1.40 * * *$ & $0.49 * *$ & 0.12 & $0.65 *$ & 0.50 & -0.08 \\
\hline $\begin{array}{l}\text { Sex } \\
\quad(\text { female }=1)\end{array}$ & $0.17 * * *$ & $-0.53 * * *$ & $-0.35^{*}$ & -0.35 & $-0.86^{* * *}$ & $-0.91 * * *$ \\
\hline \multicolumn{7}{|c|}{ Year terminating secondary educ. } \\
\hline 1932-1955 & $-1.94 * * *$ & $-1.84 * * *$ & 0.13 & 2.20 & $-1.62 *$ & 0.03 \\
\hline $1956-1965$ & -1.04 & $-1.57 * * *$ & 0.23 & 0.92 & $-0.99 *$ & 0.43 \\
\hline $1966-1975$ & -0.33 & $-1.18 * * *$ & 0.34 & $0.78 *$ & -0.48 & 0.25 \\
\hline \multicolumn{7}{|l|}{$\begin{array}{l}\text { 1976-1985 } \\
\text { (ref.) }\end{array}$} \\
\hline 1986-1995 & $0.54 *$ & $0.91 * * *$ & 0.20 & $-0.98 * *$ & -0.41 & $-0.69 *$ \\
\hline $\begin{array}{l}\text { Education } \\
\text { parents }(0-1)\end{array}$ & $3.33 *$ & $2.77 * *$ & 2.51 & -1.81 & $3.42 * *$ & 1.41 \\
\hline $\begin{array}{l}\text { Occupation } \\
\text { father } \\
\text { (ISEI 0-1) }\end{array}$ & -1.03 & 0.95 & -2.15 & -0.89 & -1.23 & -1.04 \\
\hline $\begin{array}{l}\text { Trend } \\
\text { education } \\
\text { parents }\end{array}$ & -0.32 & -0.38 & -0.45 & 0.61 & -0.63 & -0.01 \\
\hline $\begin{array}{l}\text { Trend } \\
\text { occupation } \\
\text { father }\end{array}$ & 0.45 & -0.16 & 0.68 & 0.43 & 0.48 & 0.49 \\
\hline$N$ & 1,722 & 1,650 & 806 & & 871 & \\
\hline$-2 \mathrm{LL}$ & -841.90 & $-1,006.2$ & -802.6 & & -960.4 & \\
\hline Pseudo $R^{2}$ & 13.50 & 0.12 & 0.03 & & 0.06 & \\
\hline
\end{tabular}

$* p<0.05 ; * * p<0.01 ; * * * p<0.001$

\section{References}

Bosma, H., \& Cremers, P. (1996). Sociaal-economische verschillen bij de doorstroom naar de universiteit. Mens \& Maatschappij, 71, 142-153.

Boudon, R. (1974). Education, opportunity, and social inequality. New York: Wiley.

Breen, R., \& Goldthorpe, J. H. (1997). Explaining educational differentials: Towards a formal rational action theory. Rationality and Society, 9, 275-305.

Breen, R., \& Jonsson, J. O. (2000). Analyzing educational careers: A multinomial transition model. American Sociological Review, 65, 754-772.

de Graaf, P. M., \& Ganzeboom, H. B. G. (1993). Family background and educational attainment in the Netherlands for the 1891-1960 birth cohorts. In Y. Shavit \& H. P. Blossfeld (Eds.), Persistent inequality: Changing educational attainment in thirteen countries (pp. 75-99). Boulder, CO: Westview Press.

de Graaf, P. M., \& Wolbers, M. H. J. (2003). The effects of social background, sex and ability on the transition to tertiary education in the Netherlands. Netherlands' Journal of Social Sciences, 39, $172-201$.

Dronkers, J. (1983). Have inequalities in educational opportunity changed in the Netherlands? Netherlands' Journal of Sociology, 19, 133-150. 
Erikson, R., \& Jonsson, J. O. (1996). Explaining class inequlity in education; The Swedish test case. In R. Erikson, et al. (Eds.), Can education be equalized? The Swedish case in comparative perspective. Westview: Stockholm.

Faasse, J., Bakker, B., Dronkers, J., \& Schijf, H. (1987). The impact of educational reform. Empirical evidence from two Dutch generations. Comparative Education, 23, 261-278.

Ganzeboom, H. B. G., de Graaf, P. M., \& Treiman, D. (1992). A standard international socio-economic index of occupational status. Social Science Research, 21, 1-56.

Hillmert, S., \& Jacob, M. (2003). Social inequality in higher education. Is vocational training a pathway leading to or away from university? European Sociological Review, 19, 319-334.

Jacob, M., \& Tieben, N. (2007). Social selectivity of track mobility in secondary schools. A comparison of intra-secondary transitions in Germany and the Netherlands. MZES working paper 105. Mannheim: MZES.

Jonsson, Jan. O. (1993). Persisting inequalities in Sweden? In Y. Shavit \& H.-P. Blossfeld (Eds.), Persistent inequality: Changing educational attainment in thirteen countries. Boulder: Westview Press.

Korteweg, J. A., van Leeuwen, M., de Jong, U., \& van der Veen, I. (2003). Sociaal milieu en de keuze tussen HBO en WO. Tijdschrift voor Hoger Onderwijs, 21, 2-16.

Lucas, S. R. (2001). Effectively maintained inequality: Education transitions, track mobility, and social background effects. American Journal of Sociology, 106, 1642-1690.

Mare, R. D. (1980). Social background and school continuation decisions. Journal of the American Statistical Association, 75, 295-305.

Mare, R. D. (1981). Change and stability in educational stratification. American Sociological Review, 46, $72-87$.

Mare, R. D. (1993). Educational stratification on observed and unobserved components of family background. In Y. Shavit \& H. P. Blossfeld (Eds.), Persistent inequality: Changing educational attainment in thirteen countries (pp. 351-376). Boulder, CO: Westview Press.

Müller, W., \& Haun, D. (1994). Bildungsungleichheit im sozialen Wandel. Kölner Zeitschrift für Soziologie und Sozialpsychologie, 46, 1-42.

Müller, W., \& Wolbers, M. H. J. (2003). Educational attainment in the European Union: Recent trends in qualification patterns. In W. Müller \& M. Gangl (Eds.), Transitions from education to work in Europe. The integration of youth in EU labour markets (pp. 23-62). Oxford: Oxford University Press.

Raftery, A., \& Hout, M. (1993). Maximally maintained inequality. Expansion, reform, opportunity in Irish education, 1921-75. Sociology of Education, 66, 41-62.

Rijken, S., Maas, I., \& Ganzeboom, H. B. G. (2007). The Netherlands: Access to higher education. Institutional arrangements and inequality of opportunity. In Y. Shavit, R. Arum, \& A. Gamoran (Eds.), Stratification in higher education. A comparative study (pp. 266-293). Stanford: Stanford University Press.

Schimpl-Neimanns, B. (2000). Soziale Herkunft und Bildungsbeteiligung. Empirische Analysen zu herkunftsspezifischen Bildungsungleichheiten zwischen 1950 und 1989. Kölner Zeitschrift für Soziologie und Sozialpsychologie, 52, 636-669.

Shavit, Y., \& Blossfeld, H. P. (Eds.). (1993). Persistent inequality: Changing educational attainment in thirteen countries. Boulder, CO: Westview Press.

Shavit, Y., Arum, R., \& Gamoran, A. (Eds.). (2007). Stratification in higher education. A comparative study. Stanford: Stanford University Press.

Stocké, V. (2007). Explaining education decision and effects of families ‘ social class position: An empirical test of the Breen-Goldthorpe model of educational attainment. European Sociological Review, 23, 505-519.

Tieben, N., \& Wolbers, M. H. J. (2008). Success and failure in secondary education. Effects of family background on secondary school outcome in the Netherlands, 1927-1988 (submitted).

Tieben, N., de Graaf, P. M., \& de Graaf, N. D. (2009). Changing effects of family background on transitions to secondary education in the Netherlands. Consequences of educational expansion and reform. Research in Social Stratification and Mobility, 27 (forthcoming).

van der Werfhorst, H., \& Hofstede, S. (2007). Cultural capital or relative risk aversion? Two mechanisms for educational inequality compared. The British Journal of Sociology, 58, 391-415.

Vrooman, C., \& Dronkers, J. (1986). Changing educational attainment processes. Some evidence from the Netherlands. Sociology of Education, 59, 69-78.

Webbink, H. D. (1997). Op welk niveau verder studeren na VWO of HAVO; veranderingen tussen 1982 en 1991. Tijdschrift voor onderwijsresearch, 22, 228-237. 